\title{
Energy in Australia - Peak Oil, Solar Power, and Asia's Economic Growth: a review
}

\author{
Zaman Sajid * \\ Process Engineering, Faculty of Engineering and Applied Science, Memorial University of Newfoundland, St. John's, NL, Canada \\ ${ }^{*}$ Correspondence: zaman_866@hotmail.com \\ Edited by: \\ Christos N. Markides, Imperial College London, UK \\ Reviewed by: \\ Tunde Bello-Ochende, University of Cape Town, South Africa \\ Yun Seng Lim, University of Manchester, UK \\ Mohammad Reza Hajmohammadi, Amirkabir University of Technology, Iran
}

Keywords: energy, solar, coal, oil and gas fields, life-cycle assessment, carbon pricing

\author{
A book review on \\ Energy in Australia - Peak Oil, Solar Power, and Asia's Economic Growth \\ by Graham Palmer, Springer, 2014, Springer Briefs in Energy/Energy Analysis, ISBN 978-3-319-02940-5
}

In the present book under review, the reader will have an opportunity to study and understand Australia's different energy sectors. The reader will update him/herself with the technical, environmental, and economical aspects of energy production. The book's novelty is in its discussion of the sustainability of different energy sources, ranging from non-renewable to renewable energy sources.

The book "Energy in Australia - Peak Oil, Solar Power, and Asia's Economic Growth" has been written in six chapters. The book is helpful for readers interested to learn about energy development in Australia. Students eager to learn about the economics of energy productions and the environmental impacts of energy production could also benefit from this book. The book includes a comprehensive energy analysis of rooftop solar systems along with its integration within modern electricity grid. The author provides technical depth to understand life-cycle boundaries and uses such parameters to perform energy efficient calculations for solar power in Australia. The book discusses how Australia is dependent on coal-fired electricity grids for homes despite of the fact that many homes in Australia have their own solar power systems. The author introduces the knowledge of photovoltaics (PV) in the context of modern electricity systems. The book explores the potential solar PV for Australia, since the country has unlimited sunshine throughout the year and has a modern electricity grid system. The key areas where the book focuses are solar power, rooftop solar systems, electricity system issues, energy production, utilization, and storage and more importantly, it discusses grid integration. These issues are addressed in six chapters.

Chapter 1 - "Introduction: One Million Solar Systems" presents a theoretical background behind the aims and objectives of producing this work. It highlights the need of performing life-cycle analyses and a study of energy return on investment (EROI) of using solar panels in Australian homes - the quantity of which has passed one million in March 2013.

Chapter 2 - "Quarry Australia: Building Australia on Coal" discusses the use of coal in Australia as an energy source. It discusses some pros and cons of using coal as an energy source. The chapter discusses major Australian coal based projects and highlights their economics. It also lists some of the major customers of Australian coal.

Chapter 3 - "Toward Optimized Complexity: Integrating Intermittency" provides knowledge of using 100\% renewable energy to meet Australian energy requirements. In particular, it focuses on electricity production and its use. This chapter also discusses the energy efficient processes in Melbourne, Denmark, Germany, and Spain and discusses their compactness over the technologies, which are utilized in developing such systems.

Chapter 4 - In "Electricity Networks: Managing Peak Demand," the author discusses the demand and supply of electricity at different working hours and the various factors, which effect the electricity generation. The chapter is an amalgam of knowledge about using wind as well as large-scale solar systems to meet the electricity demand.

Chapter 5 - "EROI of Solar PV" is what I consider the "heart" of the book. It discusses one of the most important factors, examining the sustainability of an energy source, the life-cycle study. The chapter discusses life-cycle assessment (LCA) of energy sources. It also develops the ways to quantify renewable energy efficiency. The chapter discusses EROI as a measurement tool. In this chapter, the author presents various case studies of energy utilization in different regions of Australia and evaluates those case studies using the LCA parameter. Palmer study is unique; in that it discusses the process inputs and outputs. Moreover, the economics of such processes accompanies with environmental studies.

The last chapter "Driving Down Emissions: The Role of Carbon Pricing" discusses one of the most important topics in today's renewable research - carbon pricing. Carbon pricing is essentially a concept introduced by Australia and has triggered a debate to have a monetary incentive 
of producing renewable energy over nonrenewable energy. Climate change is a driving force to discuss such ideas. The current chapter covers these concepts in a very systematic way. It highlights the applications of carbon pricing and at the same time, it also reveals the practicalities of such pricing. The chapter provides answers to various questions for researchers in renewable energy. It also puts forward some interesting questions, which need to be addressed by today's researchers through their findings.

Every chapter of the book is equipped with suitable references, which are helpful for the reader to study further in each respective topic and enhance their understanding of the concepts. The book helps the reader to attain an excellent understanding of the Australian energy sector and discusses energy production in its various dimensions. The author offers a valuable insight into the challenges, which are being faced by the Australian solar power systems.

Last but not the least, the book presents a momentous and meaningful debate on surplus energy in developed countries and countries without power.

Conflict of Interest Statement: The author declares that the research was conducted in the absence of any commercial or financial relationships that could be construed as a potential conflict of interest.

Received: 08 October 2014; accepted: 04 December 2014; published online: 22 December 2014.

Citation: Sajid Z (2014) Energy in Australia - Peak Oil, Solar Power, and Asia's Economic Growth: a review. Front. Energy Res. 2:60. doi: 10.3389/fenrg.2014.00060 This article was submitted to Solar Energy, a section of the journal Frontiers in Energy Research.

Copyright (c) 2014 Sajid. This is an open-access article distributed under the terms of the Creative Commons Attribution License (CC BY). The use, distribution or reproduction in other forums is permitted, provided the original author(s) or licensor are credited and that the original publication in this journal is cited, in accordance with accepted academic practice. No use, distribution or reproduction is permitted which does not comply with these terms. 